\title{
Quality of Healthcare Provided to Elderly with Type 2 Diabetes: Data from the AMD* Annals Initiative
}

Sergio Tondini ${ }^{1 *}$, Massimo Boemi ${ }^{1}$, P Marnini ${ }^{1}$, PM Bollati ${ }^{1}$, V Fiore ${ }^{1}$, Maria Chiara Rossi ${ }^{1}$, Antonio Nicolucci ${ }^{1}$, Carlo Giorda ${ }^{1}$, Antonio Ceriello ${ }^{1}$, Maria Antonietta Pellegrini ${ }^{1}$ and Diabetes in the Elderly Study Groups ${ }^{2}$

${ }^{1}$ Associazione Medici Diabetologi (AMD), Italy

${ }^{2} A M D$ National Team "Diabetes in the Elderly", Italy

\begin{abstract}
Objectives: The present study aims at exploring current approaches of Italian diabetologists, with regards to fundamental parameters in quality of care of elderly patients with type II diabetes, focusing at the same time on existing critical areas.

Research project and methodology: The results of clinical data, gathered during year 2009, were extracted from electronic medical records. The following parameters, taken from a source population of elderly people with diabetes aged $\geq 65$ years, were assessed: glycated haemoglobin ( $\mathrm{Hb} 1 \mathrm{Ac}$ ); renal function; lipid profile; arterial blood pressure; foot and eye examination. In addition, specific favorable and unfavorable outcomes of therapeutical intervention were also evaluated

Results: We assessed a total of 414,814 patients with type II diabetes in 236 diabetic centers; $39.9 \%$ were aged $<65$ years, $34.9 \%$ between 65 and 74 years and $25.2 \%>74$ years. We observed a high adherence to guidelines in the measurement of $\mathrm{Hb} 1 \mathrm{Ac}$ regardless of age, while there was a shortage in the frequency of detection of the lipid profile and blood pressure in the elderly patients. Similarly, there was a significant reduction in the percentage of patients monitored for microalbuminuria, foot and retinopathy with increasing age.

In $11 \%$ of elderly patients, $\mathrm{Hb} 1 \mathrm{Ac}$ levels were $>9 \%$, whereas in $24.9 \% \mathrm{Hb} 1 \mathrm{Ac}$ was $<6.5$. A poor lipid control was observed in about $30 \%$ of elderly patients, while the percentage of older patients lacking an optimal blood pressure control was more than twice.

Conclusions: As a whole, Italian diabetes care centers seem to provide a different quality of care to elderly type 2 diabetic patients compared to younger individuals. The data call for a higher attention for this class of frial subjects for the definition of reference objectives for elderly people.
\end{abstract}

Keywords: Diabetes; Elderly patients; AMD data file

Abbreviations: AMD: Associazione Medici Diabetologi (Italian Association of Clinical Diabetologists); BMI: Body Mass Index; GFR: Glomerular Filtration Rate; HDL: High Density Lipoprotein; LDL: Low Density Lipoprotein

\section{Introduction}

Diabetes mellitus is one of the most widespread pathologies in the world affecting about 300 million people, a figure set to increase within the next twenty years [1]. In Italy there are about 3 million people affected with different percentages in each age group. In particular, more than $50 \%$ of all outpatients cared by diabetes clinics are aged 65 years or older. This population group has multiple problems requiring a broad range of assistance and treatment, due to the fact that they are frail and/or suffer from multiple comorbidities [2]. Over the past twenty years diabetes care has significantly improved. Broad clinical studies [3-7] evaluated, along with the glycemic control, the effects of blood pressure and lipid control on the prevention of long term diabetic complications, thus contributing to the current opinion about the complexity of diabetes care. In addition, these studies have provided the basis for setting the metabolic goals in the treatment of diabetes mellitus.

From a clinical perspective approaching elder adults with long-standing diabetes often associated with microvascular and macrovascular complications or elder subjects with newly diagnosed diabetes generally leads to a different intensity of care and to different therapeutical choices. Nevertheless, in both cases the presence of frailty, disability or comorbidities associated to a shorter life expectancy brings about the need of individualizing the clinical approach from the metabolic goals to the pharmaceutical choice and from the empowerment of the patient, or of the care-giver, to the follow-up plan [8].

Despite the effort in spreading these evidences to the medical community through guidelines, these are not yet fully applied in clinical practice. Thus it is still necessary to implement all those actions necessary to reach the goal and to constantly monitor the process by specific indicators.

Since 2006 the AMD (Associazione Medici Diabetologi) Society has promoted a continuous improvement in the quality of diabetes care in Italy through its annual AMD ANNALS campaign. The campaign involves diabetes care centers throughout the entire country. All these centers electronically collect data during routine outpatient

*Corresponding author: Dott. S.Tondini, U.O. Medicina Interna, A.S.L. 9 Grosseto Via D. Alighieri, 58033 Castel del Piano(Gr), Italy, Tel: + 390564 914516; Fax: + 39 0564 914520; E-mail: s.tondini@usl9.toscana.it

Received February 23, 2015; Accepted April 26, 2015; Published April 30, 2015

Citation: Tondini S, Boemi M, Marnini P, Bollati PM, Fiore V, et al. (2015) Quality of Healthcare Provided to Elderly with Type 2 Diabetes: Data from the AMD* Annals Initiative. J Diabetes Metab 6: 542. doi:10.4172/2155-6156.1000542

Copyright: @ 2015 Tondini S, et al. This is an open-access article distributed unde the terms of the Creative Commons Attribution License, which permits unrestricted use, distribution, and reproduction in any medium, provided the original author and source are credited. 
management in order to elaborate pre-specified indicators of the care process. AMD has identified a set of indicators to be used for benchmarking activities $[9,10]$. Quality indicators include process measures evaluating diagnostic, preventive and therapeutic procedures performed by the participating centers, and outcomes indicators measuring favorable and unfavorable modifications in the patient health status.

To date, there is a lack of specific analyses on the quality of care provided to elderly population with type 2 diabetes; therefore, the aim of this study is to analyze some indicators linked to the quality of care provided by diabetes centers to young old (i.e. $\geq 65-74$ years old) and old patients (i.e. $\geq 75$ years old) as compared to younger ones in order to evaluate the attitude of Italian diabetes specialists in caring the elder population and to highlight critical areas.

\section{Materials and Methods}

\section{Selection of samples and analysis of the data}

An extensive database containing data from 251 Italian Diabetic Centers has been used.

Centers share common software for data extraction from electronic medical records. Data are collected on annual basis in a standardized format (AMD File Data) and centrally and anonymously analyzed. The entire project is conducted without allocation of extra resources or financial incentives, but simply through a physician-led effort, made possible by the commitment of the involved specialists.

We analyzed data from 414,814 subjects with type 2 diabetes that were seen in 2009 .

This extensive database is the result of the continuous improvement in the quality program, called AMD Annals campaign, promoted by the AMD Society and it reflects the usual clinical practice of Italian diabetologists.

A set of indicators has been identified for benchmarking activities:

- Process indicators: evaluating diagnostic, preventive and therapeutic procedures

- Outcome indicators: estimating favorable and unfavorable modification in patient health status

- Use of drugs (diabetic, antihypertensive, lipid-lowering)

In our study, we have analyzed the following indicators:

- $\quad$ Process measures which were taken at least once a year for the following parameters:

- Glycated haemoglobin (Hb1Ac)

- Arterial blood pressure

- Lipid profile

- Albuminuria

- Renal function - calculation of Glomerular Filtration Rate (GFR)

- $\quad$ Foot examination

- Fundus examination

- Intermediate outcomes indicators

- $\quad$ Percentage of patients with HbAlc $\leq 7 \%$
- Distribution of HbAlc level in population subgroups

- Percentage of patients with levels of cholesterol LDL $<100 \mathrm{mg} /$ $\mathrm{dl}$ and $>130 \mathrm{mg} / \mathrm{dl}$.

- Percentage of patients with blood pressure $\leq 130 / 80$ and $\geq$ $140 / 90 \mathrm{mmHg}$

- Distribution of BMI by population subgroup

- Percentage of smokers

- Percentage of patients with micro/macroalbuminuria

- Distribution of the patient for classes of GFR

In case of multiple readings collected from the same patient throughout the year, the most recent available record was taken as a benchmark.

The cholesterol LDL was estimated by the Friedwald equation. Microalbuminuria was defined as an albumin excretion rate in between 20 and $200 \mathrm{mcg} / \mathrm{min}$ alternatively both the albumin/creatinine ratio ( $>2.5$ in men or $>3.5$ in women) or a microalbumin $>30 \mathrm{mg} / \mathrm{l}$ were used for definition. The GFR was calculated with the MDRD formula (modification of the diet in renal disease).

\section{Results}

Overall, 414,814 patients with type 2 diabetes referred to 236 diabetes outpatients centers during the year 2009 were evaluated; 165,388 (39.9\%) of these patients were aged less than 65 years (young group), 144,965 (34.9\%) between 65 and 74 years (young old group), and 104,461 (25.2\%) more than 74 years (old group). Mean age was $55.8 \pm 7.8$ in the first group, $70.0 \pm 2.8$ in the second group, and 80.3 \pm 3.9 in the third group. As for the gender, in the young old group a prevalence of men (54.8\%) compared to women (45.2\%) was reported. Conversely, women were more prevalent in the older group $(54.8 \%$ vs 45.2\%).

As for the percentage of patients annually monitored for $\mathrm{HbAlc}$, there was not a significant difference among the groups being respectively $92.5 \%$ in the young, $93.3 \%$ in the young old, and $91.2 \%$ in the old group.

The percentages of young, old young and old patients with a HbA1c $<7 \%$ were respectively $43.4 \%, 45 \%$ and $42.5 \%$ respectively, while approximately $11 \%$ in both groups of elder individuals had a HbAlc $>9 \%$ compared to $16.5 \%$ in the young group. Yet, it should be considered that almost one fourth of the elder subjects had values of less than $6.5 \%$, suggesting a potential risk of hypoglycaemia (Figure 1).

The data concerning the measurement of the GFR were taken from 102,505 subjects between 65 and 74 years and from 73,099 subjects aged $\geq 74$ years, i.e. near two thirds of the population in each group and slightly less in the young group. Analyzing the distribution of the population by class of GFR, $8.4 \%$ of young and $22.4 \%$ of young old patients have a GFR lower than $60 \mathrm{ml} / \mathrm{min}$, while this percentage rose up to $40.3 \%$ in individuals older than 75 years (Figure 2).

Microalbuminuria was recorded in only $37 \%$ of subjects aged $\geq 74$ years while in those aged between 65 years and 74 years it was $42.9 \%$, a percentage equal to that observed in young individuals (42.8\%).

Annual lipid profile was lacking in $23.9 \%$ of young, $24.8 \%$ of young old and $31.9 \%$ of old group.

Total cholesterol (CT) levels tended to decrease with increasing 
Citation: Tondini S, Boemi M, Marnini P, Bollati PM, Fiore V, et al. (2015) Quality of Healthcare Provided to Elderly with Type 2 Diabetes: Data from the $\mathrm{AMD}^{*}$ Annals Initiative. J Diabetes Metab 6: 542. doi:10.4172/2155-6156.1000542

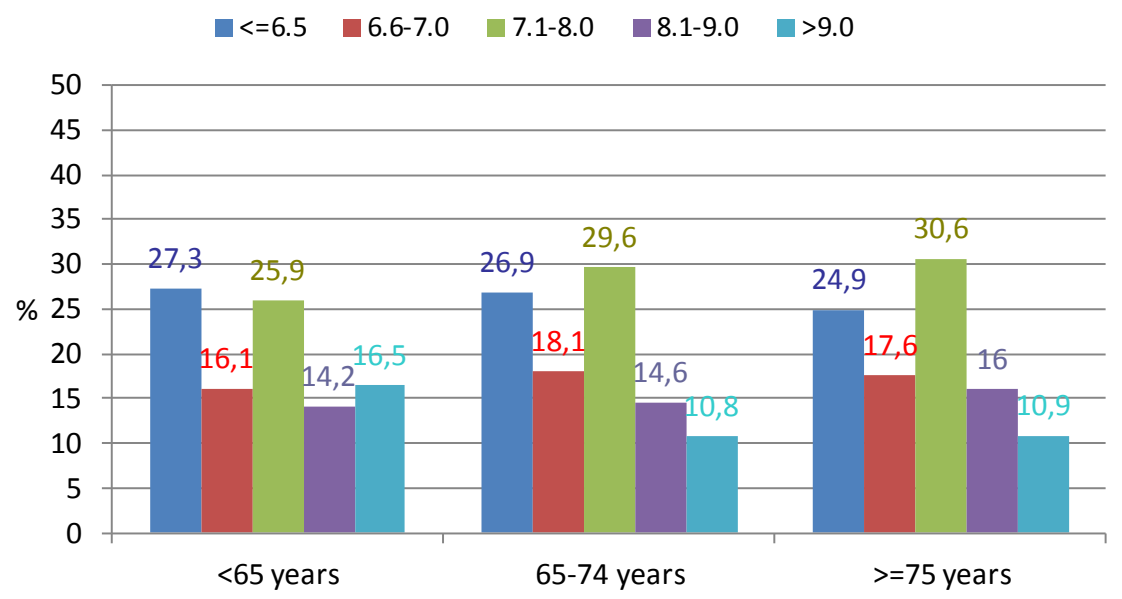

Figure 1: Trend of glycated hemoglobin by aged classes (normalized to $6 \%$ ).
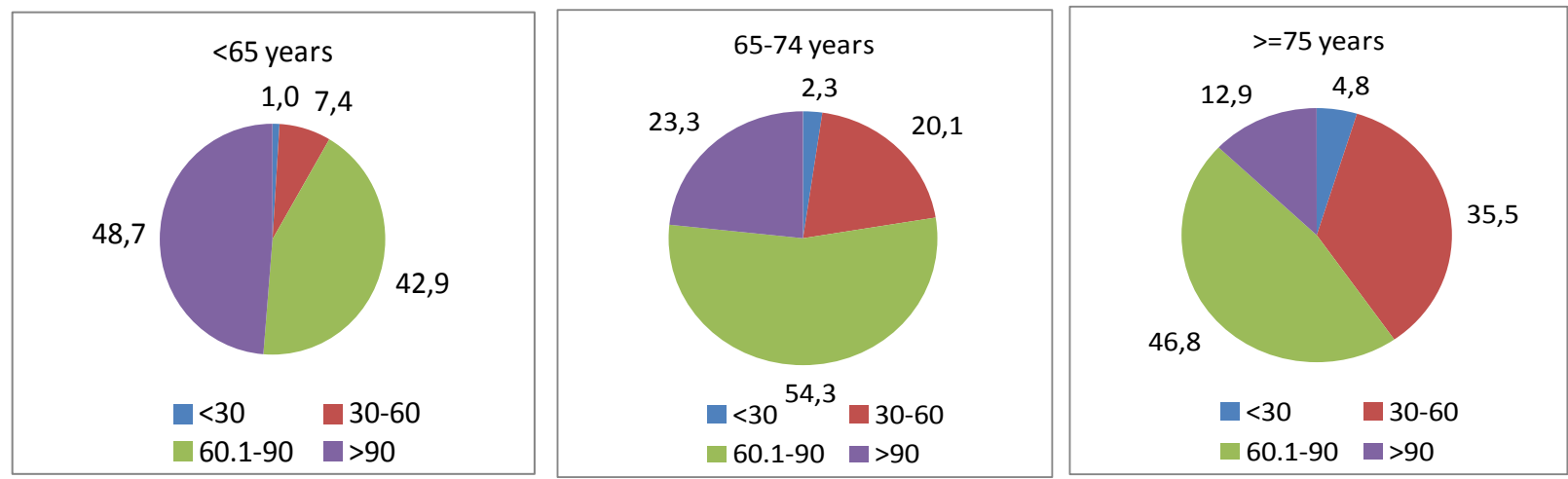

Figure 2:People distribution by GFR classes ( $\mathrm{ml} / \mathrm{min})$.

age. In diabetic individuals over 65 years, both levels of CT and C- LDL were lower as compared to younger patients.

Less than $25 \%$ of the patients aged over 65 years showed C-LDL values exceeding $130 \mathrm{mg} / \mathrm{dl}$ compared to younger patients (29.6\%).

Accordingly, the elderly population had a better lipid profile also in terms of serum triglycerides (TG) and C-HDL. With increasing age, the TG values tend to decrease, and C-HDL values both (females and males) tend to increase (Figure 3).

Measurement of arterial blood pressure was taken in $80 \%$ of young and young old patients and in $75 \%$ of old. The percentage of patients with blood pressure readings $\geq$ to $140 / 90 \mathrm{mmHg}$ increased with age being $51.1 \%, 60.3 \%$ and $62.1 \%$ respectively(Figure 4 ).

A foot examination was performed in only $14.5 \%, 13.6$ and $10.4 \%$ of the young, young old and old group respectively.

When considering only those patients at risk for foot lesions (i.e. those having a neuropathy or a low-limbs arteriopathy) the percentage of those who received a foot examination at least once a year, is still unsatisfactory, especially in the older group $(22.4 \%$ in $65-74$ years group and $19.3 \%$ in $\geq 74$ years group) but it was low even in younger people (22.5\%).

The percentage of subjects who underwent an annual examination of the fundus is similar in young and young old (35\% and 34.7\%) and very low in the old group (26.2\%).

Near $40 \%$ of patients between 65 and 74 years old, and $31 \%$ of those aged over 74 years were obese $(\mathrm{BMI} \geq 30$ ) and $26 \%$ in both groups were overweight (BMI in-between 27.0 and 29.9). In the young group obese and overweight patients were respectively $47.3 \%$ and $23.8 \%$.

The percentage of smokers was $13.8 \%$ in young old group and $7.2 \%$ in old group. The percentage of smokers is approximately twice in male than in female patients. Smokers were $25.6 \%$ among young individuals.

\section{Discussion}

The aim of this study was to evaluate possible differences in the quality of the care received by type 2 diabetic patients over 74 years compared to younger people. The study involved a large number of Italian diabetes centers involved in the AMD Annals campaign in 2009.

Quality of care was estimated by pre-specified indicators in the process area and intermediate outcomes were evaluated.

As for glycemic evaluation elder people receive the same attention as the younger. Diabetologists focus their attention on renal function (GFR evaluation) more in people over 65 years old than in those below this age while after 74 years microalbuminuria is estimated less frequently. This one may argue that while GFR is a concern for possible 


\begin{tabular}{|c|c|c|c|}
\hline & $\begin{array}{l}<65 \text { years } \\
(m \pm s d)\end{array}$ & $\begin{array}{l}\text { 65-74 years } \\
(m \neq s d)\end{array}$ & $\begin{array}{l}>=75 \text { years } \\
(m \pm s d)\end{array}$ \\
\hline Total cholesterol $(\mathrm{mg} / \mathrm{dl})$ & $191.9 \pm 42.9$ & $185.1 \pm 40.0$ & $184.7 \pm 39.9$ \\
\hline \multicolumn{4}{|l|}{$H D L$ cholesterol $(\mathrm{mg} / \mathrm{dl})$} \\
\hline Men & $45.1 \pm 12.2$ & $47.1 \pm 12.6$ & $47.7 \pm 13.1$ \\
\hline Women & $52.4 \pm 13.7$ & $53.8 \pm 14.0$ & $53.7 \pm 14.5$ \\
\hline LDL cholesterol ( $m \mathrm{~g} / \mathrm{dl})$ & $112.5 \pm 35.6$ & $106.9 \pm 33.6$ & $107.1 \pm 33.3$ \\
\hline Triglycerides $(\mathrm{mg} / \mathrm{dl})$ & $162.1 \pm 137.2$ & $141.2 \pm 85.4$ & $133.9 \pm 72.6$ \\
\hline
\end{tabular}

Figure 3: Lipid profile: mean values by age group.

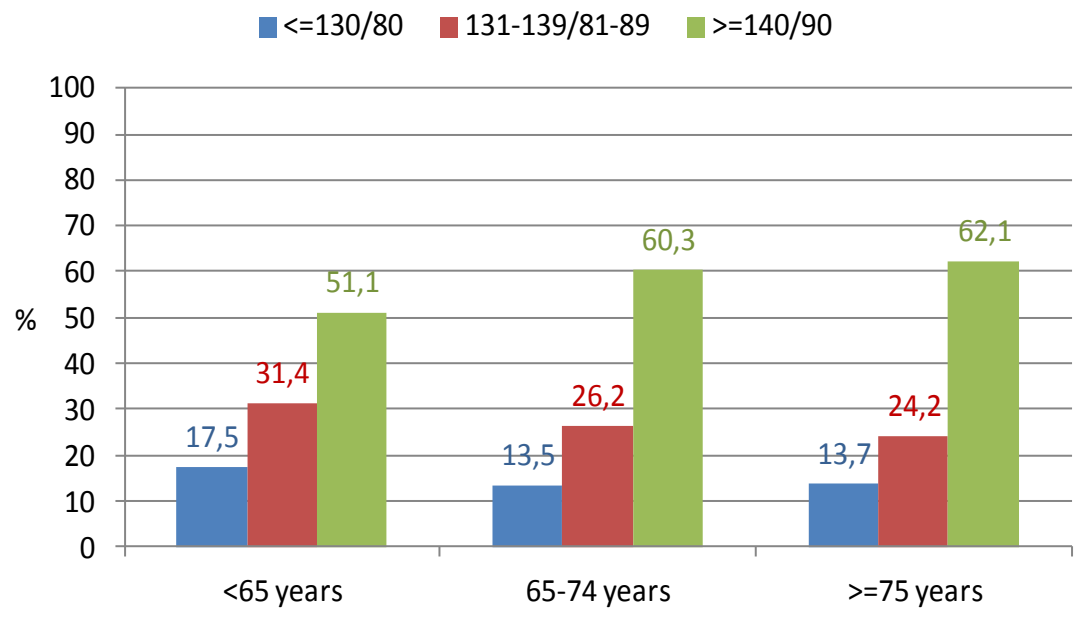

Figure 4: Trends of blood pressure values by age classes.

adverse event due to the therapy, it is not perceived as an important task to screening and follow-up of early stage of renal disease in elder individuals. This attitude is confirmed by the lower percentage of elder people undergoing an annual fundus examination compared to younger ones. Taken as a whole these results suggest that as for microvascular complications the Italian specialist care individuals aged 65-74 years in the same way of those younger than 65 years. The same picture can be depicted for the evaluation of cardiovascular risk factors such as lipids and blood pressure and for foot examination.

When considering the effect of care in terms of glycemic control, $45 \%$ of people aged $65-74$ years and $42.5 \%$ of those aged more than 74 years have an $\mathrm{HbA} 1 \mathrm{c} \%$ lower than 7 and these percentages are similar to the ones in the younger group.

Data should be interpreted taking into account the medical treatment used to achieve the target. For instance, $\mathrm{HbA1c}$ values below $7 \%$ might be inappropriate in elderly frail patients, due to the high risk of hypoglycemia; such values may be acceptable only if reached using molecules such as insulin-sensitizer or incretins. Geriatric guidelines for the type 2 diabetes management in the elderly population (over 70 years) stress this concept also in case of individuals who are not frial, indicating the $7 \%$ value of $\mathrm{HbAlc}$ as the minimum level to be reached in elder people [2]. The AMD Annals provide evidence about one of the most common long-term complication of diabetes, the kidney function impairment. Results in term of HbAlc in the elderly population should be evaluated in relation to this variable, as it determines the risk of adverse events linked to the therapy. Conversely, more than one in ten individuals observed has a significantly high level of HbA1c. These levels might be primarily associated with the development or the worsening of geriatric syndromes [11], cognitive decline and incontinence, and therefore, like excessively low levels, they should be avoided.

GFR declines with age. The levels of GFR and the levels of albuminuria are useful for an adequate evaluation of the stage of renal disease [12] and their values give complementary information.

In $24 \%$ of type I diabetic patients, a reduction of GFR in the absence of albuminuria has been reported [13], this percentage is even higher in type 2 individuals ranging from between 39 to $62 \%$ [14]. Even more significant results were found in the Italian Study RIACE [15], where three-quarters of the population studied were aged over 60 years and a prevalence of $56.6 \%$ in the non-albuminuric form in diabetic patients with CKD stage 3 or more was observed, whereas only $30.8 \%$ and $12.6 \%$ were respectively micro and macroalbuminuric. Several studies have confirmed the relationship between GFR, albuminuria and increased 
incidence of cardiovascular events [16,17]. In the RIACE study [15], a strong association between coronary events and reduction of the GFR was observed, while for cerebrovascular and peripheral vascular disease a close association with the albuminuric phenotypes, indicating a different clinical pathogenesis, was reported. Thus specialists must pay the same attention in evaluating both the variables.

It has been clearly demonstrated how the reduction in lipid levels, particularly LDL-C, induce a significant reduction in terms of disease status and death from cardiovascular disease [18] and that this effect can be appreciated, after only three years of treatment, much earlier than the effect of a good glycemic control [19].

Guidelines shared by the principal scientific societies have not indicated a specific target in the management of hypercholesterolemia in the elderly, especially in the diabetic population [20].

Resting on the effectiveness of lipid lowering therapy in individuals below 80 years old, the same objectives for younger people are recommended for very old people in both primary and secondary prevention [21].

Our elder population showed a better lipid profile than the younger. These results can be interpreted in different ways but a survival effect is likely. It is remarkable that HDL-C and triglycerides values are respectively higher and lower in the young old and old subgroups were obese patients were less represented.

Yet, it is necessary to consider that the treatment of the elderly with hypercholesterolemia must be individualized, taking into consideration both age and cardiovascular risk, as well as the general function and grade of independence and disability, as recently proposedand carefullyweighing the risks and benefits of statin therapy $[22,23]$.

With increasing age a large part of patients show pressure readings higher than 140/90. In particular, there is an increase in systolic value and the relative cardiovascular risk.

The treatment of hypertension in the elderly is associated with a significant reduction in the mortality from cardiovascular and microvascular complications [24]. It has been widely demonstrated that the reduction of circulatory complications occurs after at least 8 years of good glucose control. Yet, in case of regular control of blood pressure, the benefits are already evident after 2-3 years [25].

Antihypertensive treatment in the elderly is highly effective in reducing cardiovascular events when blood pressure is reduced below $140 \mathrm{~mm} \mathrm{Hg}$, but it loses its effectiveness with further reduction.

The guidelines from the American Society of Geriatrics [25] state that the acceptable blood pressure to achieve, for whatever therapy undertaken, is equal to or less than $140 / 90$, where tolerated. However, it is potentially harmful to reach values under $120 \mathrm{mmHg}$ because of the risk of hypotension and falls [16,26,27].

However, given the considerable heterogeneity of the elderly, the American Diabetes Association guidelines advice target blood pressure $<140 / 80 \mathrm{mmHg}$, recommending aims that are less constricting for elderly patients that have low life expectancy [28].

Feet were examined only in one fifth of the patients and even less in the age group over 75 years. The data collected indicate an important critical area, considering that the patients at risk are diabetic individuals with neuropathy, a history of diabetic foot, progressive amputations or arterial obstructive disease in the lower limbs. All diabetic individuals should undergo at least once a year a complete check up of their feet.
Particular attention must be given to patients over 70 years, and the following aspects must be considered: social, assistance, comorbidity, fragility and other circumstances increasing the risk of developing the "diabetic foot". This critical finding on foot examination is an issue for the diabetes teams in Italy and claim for a different organization.

In this regard, it is necessary to identify and assign specific tasks to the support systems in primary and secondary care that are interdependent on similar programs, involving also general practitioners who can play a key role in preventive care [29].

Diabetic retinopathy is the most threatening among the chronic microvascular complications of diabetes for elderly patients; the incidence of blindness is 6-12 case/100,000 inhabitants/year over 70 years of age and the strongest predictor of retinopathy is the duration of diabetes [30]. Considering the effects of visual loss in type 2 diabetes, patients should be screened for diabetic retinopathy at the time of diagnosis. The following examinations should be programmed at least every two years, and even more frequently in cases of diabetic retinopathy [21].

Diabetes centers must be supplied with devices and/or facilities necessary to follow up examinations. It is recommended to cooperate with thenearesteye clinics and to involve patients in educational courses about the prevention and early diagnosis of diabetic retinopathy, in order to improve self-education [21].

In addition to check ups, good metabolic balance, adequate control of blood pressure, and reduction in the cardiovascular risk factors reduce the risk and progression of diabetic retinopathy [31,32].

Obesity tends to be less prevalent in very old patients. This could be related to the fact that the most overweight patients died prematurely; however, it should be noted that with increasing age, the BMI loses its value as an index for obesity, mainly due to the progressive reduction in height, and its predictive powers on mortality [33].

The percentage of smokers was lower in both sexes with increasing age. This phenomenon could depend on a higher number of discontinuations, related to the increase in comorbidity, in particular those due to cardiovascular problems predisposed by smoking.

Nonetheless, the number of smokers over seventy-five years of age ( 1 out of 10 men and almost 1 out of 20 women) is still very impressive, and it suggests that there is need for a greater commitment by doctors in this field.

\section{Conclusions}

Despite the high level of diabetes care in Italy compared to other Western Countries some areas are still critical and a gap between guidelines recommendations and clinical practice is evident. This gap is more evident in elder people over 74 years of age. In this subgroup, that is by definition the one in need of higher attention, the Italian specialists underestimate the risk for both acute and long-term complications.

Finally, our results can be partially biased by the fact that physicians may omit to record the result of a carried out procedure but the large number of centers and of subjects included in the study make the results reliable.

Thus, any effort should be made by the cultural and organizational perspective to overcome the existing gap.

\section{Acknowledgments}

The authors of this paper gratefully acknowledge the support given by the researchers participating in the AMD Annals Initiative. 
Editorial Board (in alphabetical order): Adolfo Arcangeli - Prato, Antonino Cimino - Brescia, Paolo Di Bartolo - Ravenna, Danila Fava - Roma, Augusto Lovagnini-Scher - Cusano Milanino (MI), Alberto Marangoni - Bassano Del Grappa (VI), Illidio Meloncelli - S. Benedetto del Tronto (AP), Maria Franca Mulas - Oristano, Antonio Nicolucci, Santa Maria Imbaro $(\mathrm{CH})$, Andrea Nogara - Chioggia, Fabio Pellegrini, Santa Maria Imbaro (CH), Maria ChiaraRossi - Santa Maria Imbaro $(\mathrm{CH})$, Salvatore Turco - Napoli, Giacomo Vespasiani -S. Benedetto del Tronto (AP)

Statistical analysis: Antonio Nicolucci, Maria Chiara Rossi, Fabio Pellegrini, Giuseppe Lucisano, Basilio Pintaudi, Marco Scardapane, Riccarda Memmo, Elena Pellicciotta, Fondazione Mario Negri Sud, Santa Maria Imbaro $(\mathrm{CH})$.

Regional Tutors (in alphabetical order by region): La Penna G, Paciotti V,- Abruzzo; Venezia A - Basilicata; Armentano G, Giovannini C - Calabria; Armentano V, Laudato M, Turco S - Campania; Laffi G, Monesi M - Emilia Romagna; Felace G, Tortul C - Friuli Venezia Giulia; Santantonio G, Suraci C - Lazio; Ghisoni G, Raffa M - Liguria; Genovese S, Lovagnini-Scher CA, Mangone I, Richini D, Rocca A - Lombardia; Garrapa G, Tortato E - Marche; Vitale C - Molise; Comoglio M, Fornengo R - Piemonte; De Cosmo S, Gentile FM Puglia; Gigante A, Mastinu F - Sardegna; Di Benedetto A, Saitta G - Sicilia; Calabrese M, Orsini P - Toscana; De Blasi G, Romanelli T - Trentino Alto Adige; Cicioni G, Pocciati S - Umbria; Marangoni A, Nogara A - Veneto.

Participating centres (in alphabetical order by town):Marilena Lanero, Carla Bergonzini, Maria Grazia Bertero, Alba Rapetti, Gabriella Martini, Monica Tornaghi - Acqui Terme (AL); Antonino Pipitone, Lucio Bellinetti, Gemma Frigato, Daniela Santipolo - Adria (RO); Massimo Boaretto, Luisa Parmesan, Barbara Conte, Iva Manfroi, Fanny Soccol, Nadia Cumina - Agordo (BL); Annamaria Nuzzi, Elisabetta Benedusi Pagliano, Emanuele Fraticelli, Paola Viberti, Antonietta Pasquero - Alba (CN); Adalberto Pagano, Enrico Papini, Marco Chianelli, Filomena Graziano, Irene Misischi, Lucilla Petrucci, Roberta Rinaldi, Stefania Silvagni - Albano Laziale (RM); Maura Rosco - Alberobello (BA); Egle Ansaldi, Francesco Malvicino, Maurizia Battezzati, Paolo Maresca, Marcella Balbo, Clara Palenzona Alessandria; Giovanni Cicioni, Stefania Venturi - Amelia (TR); Valentino Cherubini, Antonio Iannilli, Martina Biagioni, Chiara Giorgetti, Maria Cristina Alessandrelli, Alessandra Cesaretti, Anna Maria Paparusso - Ancona; Massimo Boemi, Rosa Anna Rabini, Gabriele Brandoni, Federica D’Angelo - Ancona; Maria Luigia De Cicco, Federica Giampetruzzi, Filomena Loconte, Simona Maldera, Stefania Annese, Palma Di Corato, Daniela Strippoli, Tiziana Rizzi Andria (BAT); Giulio Doveri, Emma Lillaz, Antonio Ciccarelli, Salvatore Giardina, Roberta Courthoud, Paola Mararia, Elisa Pascale, Silvana Flou - Aosta; Grazia Pia Ricciardi, Paola Di Masa - Aprilia (LT); Guido Vitalone, Donatella Setti, Giuseppe Piticchio, Patrizia Contrini, Camilla Mazzola - Arco (TN); Paola Ponzani, Valeria Ghigliotti, Andrea Corsi - Arenzano (GE); Vincenzo Mazzini, Marina Orlandi, Maria Cristina Pollace - Argenta (FE); Stefano Fazion, Maria Luisa Spina, Cinzia Francesconi - Asola (MN); Vincenzo Trosini, Roberto Berardinucci, Katia Dolcetti, Paola Colleluori, Emanuela Cannarsa, Valeria Montanari, Paolo Di Berardino - Atri (TE); Mario Velussi - Aurisina (TS); Vincenzo Paciotti, Pasquale Alfidi, Bruno Verdecchia, Luigina Baliva, Alessia Di Pietro, Giovanna Franchi, Patrizia Luce - Avezzano (AQ); Simona Flora Maldera, Mariangela Manicone, Daniela Strippoli, Ida Console, Rossella Caringella, Anna Leonardini, Michele Giardino, Giuseppe Stornelli, Cristina
Palmiotto,Gianluca Besozzi, Daniela Di Marzo, Adriana Lategola,Alessandra Marcotrigiano, Paolo Sciascia - Bari; Alberto Marangoni, Alessandro Pianta, Maria Ferrari, Sara Balzano, Gianpietro Beltranello - Bassano Del Grappa (VI); Massimo Boaretto, Concetta Nadia Aricò, Corradina Alagona, Laura Cervo, Silvia Rossa, Rosella Zanon - Belluno; Franco Travaglino, Rita Graziella Guarnieri - Biella; Maura Rosco, Maria Concetta Di Pace - Bisceglie (BAT); Gilberto Laffi, Silvio Giangiulio, Michele Grimaldi, Giovanna Santacroce, Fernanda Cerrelli, Rita Manini, Adolfo Ciavarella - Bologna; Stefano Zucchini, Claudia Balsamo, Mirella Scipione, Giulio Maltoni, Alessandra Rollo - Bologna; Bruno Fattor, Tiziano Monauni, Florian Amor, Dalia Crazzolara, Gerhard Orion, Michela Cristini, Sylvia Lintner,Johanna Eisath - Bolzano; Laura Chiappini, Sandra Alberti Bondeno (FE); Stefano Garavelli, Teresa Calari, Paola Marini - Borgo Valsugana (TN); Marco Buschini, Daniela Bonfiglioli, Damiano Mones - Borgomanero (NO); Aldo Giuseppe Morea, Lucia Bondesan, Sandro Perbellini - Bovolone (VR); Emanuele Fraticelli, Mauro Ravera - Bra (CN); Antonino Cimino, Umberto Valentini, Angela Girelli, Liliana Rocca, Barbara Agosti, Emanuela Zarra - Brescia; Gianfranco De Blasi, Michael Bergmann, Franz Plaickner, Alessandra Ferro Ingaglio, Irmgard Pradi, Marianne Piok, Rosmarie Unterkircher, Marion Pichler - Bressanone (BZ); Giuseppina Palamà, Patrizia Palma, Claudia Pisanello, Antonio Trinchera - Brindisi; Brigitte Viehweider Brunico (BZ); Mauro Giovanni Schiesaro, Giovanni Vita, Beatrice Cenci, Laura Pizzamiglio - Bussolengo (VR); Francesca Spanu, Sandro Cocco, Rasangela Maria Pilosu, Pier Paolo Contini - Cagliari; Giampiero Piras, Roberto Seguro, Marco Songini - Cagliari; Marco Stabilini, Fabrizio Lombardini, Salvatorina Mura, Paola Sulis, Aldo Caddori - Cagliari; Maria Giulia Cartechini, Natalia Busciantella Ricci, Giacoma Agostinelli - Camerino (MC); Antimo Aiello, Maria Rosaria Cristofaro, Lorenzo Cocco, Simonetta Di Vincenzo, Fiorentina D’Amico, Vittoria Di Iorio, Franca Di Ponte, Graziella Giancola, Emanuela Mazzola, Vittoria Niro, Lina Notartomaso, Carmela Sabetta - Campobasso; Annamaria Nuzzi, Claudia Ballauri - Canale (CN); Sergio Casati, Daniela Tettamanzi, Margherita Casartelli, Cosimo Prete, Emanuela Gatti, Luisa Marzorati, Tiziana Cairoli - Cantù (CO); Annelisa Lesina, Francesco Romeo, Carlo Bruno Giorda, - Carmagnola (TO); Anna Vittoria Ciardullo, Daniela Piani, Angela Deroma, Ewa Grazyna Maciejewska, Veronica Baccini - Carpi (MO); Elisabetta Straface - Casalbordino (CH); Giuseppe Pozzuoli, Mario Laudato, Maria Barone - Caserta; Sergio Tondini, Flavia Borgoni - Castel del Piano (GR); Juliette Grosso, Loredana Rossi, Carla Scarsellato, Antonietta Sciulli, Federica De Marco - Castel di Sangro (AQ); Stefano Fazion, Maria Luisa Spina, Cinzia Francesconi - Castel Goffredo (MN); Loris Confortin, Narciso Marin, Mario Lamonica, Elisa Rossi, Anna Pisacane, Vanessa Cavasin - Castelfranco Veneto (TV); Stefano Genovese, Fabiana Locatelli, Valeria Valdes, Flavia Moratti, Valentina Fuso - Castellanza (VA); Giordano Filippi, Monica Camporesi, Mirca Gherardi - Castelnovo Ne' Monti (RE); Sergio Gallana, Gloria Buganza, Adriana Valentini, Ilaria Cera - Castiglione delle Stiviere (MN); Salvatore Gialdino, Rossella Franchino - Castrovillari (CS); Vito Borzì, Concetta Gatta, Riccardo Rapisardi, Salvatore Strano, Maria Calabrò Catania; Luigi Puccio, Raffaella Vero - Catanzaro; Giuseppe Cheluci, Susy Martucci, Anna Simoncelli, Maria Pia Giammoema, Bruna Seber, Mauro Lozzer, Sonia Andolfatto - Cavalese (TN); Gemma Frigato Cavarzere (VE); Vincenzo Starnone, Andrea Del Buono, Anna Maria Terracciano, Egidio Gamba - Cellole (CE); Vincenzo Maria Monda, Paola Ramponi, Sandra Alberti, Elisabetta Maccaferri, Flavia Busi Cento (FE); Francesco Castro, Antonello Guaglianone, Concezione Maccari - Cetraro (CS); Laura Corsi, Giorgio Versari, Maria Rosaria Falivene, Nicoletta Boletto, Simona Corsi, Marisa Delucchi, Simonetta 
Gasperi, Bruna Ferrari - Chiavari (GE); Carla Origlia, Lisa Marafetti, Carlo Bruno Giorda - Chieri (TO); Ester Vitacolonna, Livia Lina Cavuto, Federica Fraticelli, Matteo D’Angelo - Chieti; Loredana di Nisio, Filomena Simonetti - Chieti; Andrea Nogara, Gianni Ballarin, Angelo Boscolo Bariga, Silvia Di Benedetto - Chioggia (VE); Anna Maria Chiambretti, Riccardo Fornengo, Lidia Di Vito, Maria Divina Pascuzzo, Paola Urli, Monica Albertone, Primo Bassani, Carla Bellaluna, Maria Bonacci, Iolanda Bosso, Daniela Cortale, Vanda De Michelis, Margherita Di Gennaro, Vilma Magliano, Silvia Nieddu, Antonia Stranisci - Chivasso (TO); Alberto Rocca, Paola Galli, Annunziata De Blasi, Monica Castellan, Cristina Cavenaghi, Maria Iagulli - Cinisello Balsamo (MI); Virginia Trinelli, Francesco Caraffa, Daniela Gallo - Ciriè (TO); Roberto Norgiolini, Roberta Celleno, Corrado Campanelli, Daniela Biccheri, Cinzia Bondi, Giuseppa Dadi Città di Castello (PG); Graziano Santantonio, Luciano Massa, Alessandra Zappaterreno, Lina Lottatori, Elisa Costanzo, Nicoletta Pistola - Civitavecchia (RM); Paolo Ziller, Federica Portolan, Giuseppe Pasolini - Cles (TN); Valerio Di Chiara, Maria Luisa Grata, Elisabetta Bergami, Soccorsa Ciannillo, Navia Curzola - Codigoro (FE); Luigi Capretti, Guglielmina Speroni, Luciano Fugazza - Codogno (LO); Cinzia Massafra - Cologno Monzese (MI); Maria Cristina Cimicchi, Carlo Percudani, Tiziana Risolo, Paola Saccò, Manuela Mori - Colorno (PR); Valerio Di Chiara, Maria Luisa Grata, Elisabetta Bergami, Soccorsa Ciannillo, Navia Curzola - Comacchio (FE); Gian Luigi Gidoni Guarnieri, Diana Piccolo, Franca Giacon, Mariolina Scarpel, Clementina Bravin, Elena De Noni, Vanda Daniotti - Conegliano (TV); Giuseppe Panebianco, Federica Tadiotto, Virgilio Da Tos, Michele D'Ambrosio, Monica Faoncella, Marj Zogno, Cristina Lunardi, Patrizia Crivellaro, Loretta Trivellato - Conselve (PD); Dario Pellizzola, Maria Antonella Zampini, Emanuela Frezzati, Maria Elvira Raminelli, Elena Mari - Copparo (FE); Dario Gaiti, Giuseppina Chierici, Silvia Pilla, Bruna Milli, Monica Camporesi, Paola Caretta, Valeria Vezzani, Melita Copelli - Correggio (RE); Alfonso Longobucco - Cosenza; Patrizia Ruggeri, Sergio Di Lembo, Elisa Carrai, Amalia Degli Innocenti, Lucia Manini, Romano Persico, Cristiana Rossi - Cremona; Enrico Gabellieri, Daniela Sansone, Maria Stella Sbriglia, Giuseppina Comba, Giovanni Valesano, Stefania Bertello, Luisella Ballatore, Salvatore Oleandri - Cuneo; Giampaolo Magro, Francesco Tassone, Donatella Gaviglio - Cuneo; Giuseppe Marelli, Veronica Vilei, Paolo Rumi, Laura Bellato, Mara Fedeli, Antonella Merlini, Giuseppina Pinelli Desio (MB); Giuseppe Marin, Maria Luisa Contin, Angela De Cata, Anna Patalano, Paola Parlato, Jessica Jacovacci - Dolo (VE); Giuseppe Placentino, Vittoria Zizzari, Sofia Pellanda, Luisa Folchi, Anna Lorenzini - Domodossola (VB); Donata Richini, Stefano Molinari, Chiara Inversini, Roberto Strazzieri, Paolo Stofler, Marco Andreoli, Simona Fornaro - Esine (BS); Giuseppe Panebianco, Federica Tadiotto, Virgilio Da Tos, Michele D'Ambrosio, Monica Faoncella, Marj Zogno, Cristina Lunardi, Patrizia Crivellaro, Loretta Trivellato - Este (PD); Maria Simona Termine, Paolo Di Bartolo - Faenza (RA); Luisella Cotti, Gabriella Garrapa - Fano (PU); Ferruccio D’Incau, Patrizia Lagomanzini, Paola Conte, Fiorina Todesco - Feltre (BL); Paolo Foglini, Elena Tortato, Paola Pantanetti, Sandra Di Marco, Rossana Maricotti, Claudio Bedetta - Fermo; Franco Tomasi, Marcello Monesi, Roberto Graziani, Lucia Penna, Fausto Beretta, Chiara Zamboni Ferrara; Antonella Guberti, Davide Dazzi, Nicoletta Orlandi - Fidenza (PR); Luca Lione, Gigi Bocchio, Edmondo Bosco, Gianmario Massazza, - Finale Ligure, Loano, Pietra Ligure (SV); Sergio Pocciati - Foligno (PG); Elisa Forte, Concettina Marrocco, Antonella Griffo, Roberta Moschetta - Fondi (LT); Tuccinardi Franco, Francesco De Meo, Elisa Forte, Antonietta Coppola, Raffaele Vallefuoco, Pina Pirolozzi, Vincenzo Placitelli - Gaeta (LT); Arturo Mastropasqua, Paolo Marenco
- Garbagnate Milanese (MI); Claudio Taboga, Barbara Catone Gemona del Friuli (UD); Alberto Aglialoro, Giovanni Careddu, Roberta Guido, Maurizio Patrone, Madina Dagnino, Adelina Massara, Margherita Zecchini, Andrea Corsi - Genova; Micaela Battistini, Francesca Fabbri, Vilma Campora, Patrizia Carosla, Silvana Chinigò, Andrea Corsi - Genova; Guglielmo Ghisoni, Francesca Fabbri, Marina Torresani, Roberto Crovetto, Andrea Corsi - Genova; Giorgio Luciano Viviani, Arianna Durante, Francesca Pais, Vittorio Lilliu - Genova; Maura Rosco, Cornelia Mzzaraco - Gioia del Colle (BA); Ercole D’Ugo, Mariarosaria Squadrone, Tommaso Amenduni, Maria M Iovannisci, Flora Potente, Teresa Delle Donne, Concetta Massa, Luigi Della Penna - Gissi $(\mathrm{CH})$; Silvestro De Berardinis, Ilde Guarnieri, Marina Splendiani, Rosanna Di Giuseppe, Susanna Lupidii, Rosanna Ruggieri, Sabrina D'Antonio, Antonella Valorosi - Giulianova (TE); Barbara Brunato, Roberta Assaloni, Rosalia Loro, Sandro Bucciol, Raimonda Muraro, Roberto Da Ros, Carla Tortul - Gorizia; Maura Rosco, Chiara Lavacca - Gravina (BA); Fabrizio Quadri, Gigliola Sabbatini, Laura Sambuco, Clorinda Santacroce - Grosseto; Giuseppina Chierici, Silvia Pilla, Bruna Milli, Melita Copelli, Lorella Bertelli, Pietro Zanichelli, Simona Bodecchi, Susanna Rovesti - Guastalla (RE); Cecilia Marino, Augusta Micheletti, Annarita Petrelli; Valentina Pasquini - Gubbio (PG); Angelo Corda, Luisa Pisano, Giacomo Guaita, Cinzia Deias, Paola Marino, Giuseppa Cuccu, Tina Poggi, Arianna Marceddu, Susanna Diana - Iglesias (CI); Giuliana Baldassarri, Anna Vacirca Imola; Maria Antonietta Fois, Valentina Maria Cambuli, Ada Pilia, Rosa Pilia, Giuliana Cao - Isili (CA); Mauro Giovanni Schiesaro, Giovanni Vita, Daniele Bonato, Katia Poletto - Isola della Scala (VR); Stefania Deiana, Francesca Scanu - Ittiri (SS); Giorgio Trevisan - Jesolo (VE); Rossella Iannarelli, Enrico Storelli, Alessandra Sperandio,Filomena Sciarretta, Romana Cialfi - L'Aquila; Alberto Zappa, Stefano Carro, Laura Dreini, Sonia Valesi, Giovanna Cinguetti, Roberta Parentini, Alessandra Guazzetti, Cristina Pennucci - La Spezia; Ercole D'Ugo, Daniela Antenucci, Anita Minnucci, Angela Bosco, Giovanna Angelicola, Angela Di Federico, Giuseppina Di Marco, Rosanna Fresco, Claudia Di Florio - Lanciano $(\mathrm{CH})$; Diletta Ugolotti, Clelia Di Seclì, Ilaria Boselli, Tiziana Cadossi - Langhirano (PR); Albino Massidda, Gisella Meloni, Claudia Putzu, Carlo Cozzi - Lanusei (NU); Raffaella Buzzetti, Camillo Gnessi, Gaetano Leto, Chiara Foffi, Laura Cipolloni, Chiara Venditti, Chiara Moretti, Angela Carlone Latina; Aldo Giuseppe Morea, Lucia Bondesan, Sandro Perbellini Legnago (VR); Aurora Valicenti, Stefania Bertoli, Sabrina Cosimi, Sandra Bianchini - Lido di Camaiore (LU); Stefano Genovese, Valeria Valdes, Dina Miele - Limbiate (MB); Graziano Di Cianni, Paola Orsini, Anna Turco, Cristina Lencioni, Chiara Goretti, Claudia Sannino, Paolo Lemmi - Livorno; Maura Rosco - Locorotondo (BA); Alberto di Carlo, Ilaria Casadidio, Ilaria Cuccuru, Laura Maria Chiara Giorgi, Alba Galli, Marzia Piacentini, Elisa Del Bianco, Chiara Russo, Piera Baroni, Antonella Salvini, Vito Michele Cassano - Lucca; Piero Melandri, Paolo Di Bartolo - Lugo (RA); Gabriele Maolo, Barbara Polenta, Nadia Piccinini - Macerata; Maria Maddalena Atzeni, Cristina Porru Macomer (NU); Cesare Vincenti, Paola Mega, Enza Magurano, Nicola Pastore, Antonella Cananiello - Maglie (LE); Giuliano Gaspardo, Elettra Brussa Toi, Ciro Antonio Francescutto, Luisa Angeli, Lorena Ronchese - Maniago (PN); Stefano Fazion, Francesca Saggiani, Linneo Enzo Mantovani, Adriana Forapani, Raffaella Antoniazzi, Paola Cristianini, Rita Mazzali, Elena Pierobon - Mantova; Salvatore Turco, Anna Amelia Turco, Maria Teresa Fernicola, Giuseppe Cudemo, Giovanna Taglialatela - Marano di Napoli (NA); Luigi Sciangula, Alessandra Ciucci, Myriam Gandolfo, Baldassarre Grassa, Adele Tono, Rosalia De Marco, Emanuela Simona Olivo, Elisa Bellini - Mariano Comense (CO); Antonino Lo Presti, Antonietta Maria Scarpitta - 
Marsala (TP); Maria Adelaide Dolci, Fabio Baccetti, Giovanna Gregori, Mary Mori - Massa (MS); Alessandro de Palma, Massimo Alessandri, Paola Sarenari, Cecilia Panni, Ornella Vagnetti, Carla Petri - Massa Marittima (Gr); Angelo Venezia, Roberto Morea, Giuseppe Lagonigro, Giovanni Copeta, Valeria Iannucci, Vittoria Milano, Maria Trupo Matera; Alberto Casartelli, Giampaolo Scollo - Menaggio (CO); Paolo Emilio Marchetto, Andreas Lochmann, Gianpiero Incelli, Simon Rauch, Anita Stadler, Sonja Breitenberger, Maria Magdalena Steiger, Maria Anna Gamper, Manuela Holzner - Merano (BZ); Claudio, Lambiase, Teresa Di Vece, Maurizio D’Aniello, Luigi Gargiulo, Anna Vitale, Massimo Fezza, Carmela Giordano, Flora Leo - Mercato S. Severino (SA); Antonino Di Benedetto, Domenico Cucinotta, Giacoma Di Vieste, Basilio Pintaudi, Giuseppina Russo - Messina; Giovanni Saitta - Messina; Manuela Moise - Mestre (VE); Lucilla D Monti, Emanuele Bosi - Milano; Nicoletta Musacchio, Annalisa Giancaterini, Augusto Lovagnini Scher, Ilaria Ciullo, Laura Pessina, Silvia Maino, Rosanna Gaiofatto - Milano; Giampaolo Testori, Pietro A Rampini, Nadia Cerutti, Paola S Morpurgo, Giacomo Bonino, Francesca Morreale - Milano; Alfredo Zocca, Barbara Aiello, Maurizio Picca Milano; Loris Bortolato, Alessandra Cosma, Giuseppe Donà - Mirano (VE); Giuseppe Campobasso - Modugno (BA); Francesco Mario Gentile, Giovanna Mazzotta - Mola di Bari (BA); Marco Comoglio, Roberta Manti, Carlo Bruno Giorda - Moncalieri (TO); Carla Tortul, Roberto Da Ros, Raimonda Muraro, Silvana Carlucci, Lorena Narduzzi, Laura Stanic, Elisabetta Bain, Anna Martignon, Monique Pellegrin Monfalcone (GO); Giuseppe Panebianco, Federica Tadiotto, Virgilio Da Tos, Michele D'Ambrosio, Monica Faoncella, Marj Zogno, Cristina Lunardi, Patrizia Crivellaro, Loretta Trivellato - Monselice (PD); Giuseppe Panebianco, Federica Tadiotto, Virgilio Da Tos, Michele D’Ambrosio, Monica Faoncella, Marj Zogno, cristina lunardi, Patrizia crivellaro, Loretta Trivellato - Montagnana (PD); Antonio Volpi, Anna Coracina, Anna Maria Cospite - Montebelluna (TV); Valeria Manicardi, Massimo Michelini, Lorenzo Finardi, Francesca Borghi, Elisa Manicardi, Rosa Trianni - Montecchio Emilia (RE); Simonetta Lombardi, Michele Iaccarino, Silvana Costa, Chiara Tommasi, Sabrina Cozza, Federica Marini, Isabella Mecenero, Stefania Massignani Montecchio Maggiore (VI); Marco Giorgio Baroni, Efisio Cossu, Elena Loy, Marta Tuveri - Moserrato (CA); Paola Pisanu - Muravera (ca); Vincenzo Armentano, Oreste Egione, Sergio Galdieri, Anna Velotti, Gemma Annicelli, Francesco De Lillo, Antonino Azzolina - Napoli; Giuseppe Cozzolino - Napoli; Angelo Foglia, Giovanna Monfregola Napoli; Adriano Gatti, Raffaele Giannettino, Michele Bonavita, Eugenio Creso - Napoli; Sandro Gentile, Giuseppina Guarino, Giampiero Marino, Adele Esposito - Napoli; Nicolangelo Iazzetta, Adriana Cammarota - Napoli; Nicolangelo Iazzetta, Claudio Giannattasio - Napoli; Salvatore Turco, Ciro Iovine, Anna Amelia Turco, Gabriele Riccardi - Napoli; Luciano Zenari, Lorenzo Bertolini, Claudia Sorgato, Francesca Grippaldi - Negrar (VR); Mauro Stroppiana, Silvia Abate, Natalia Carbone, Iolanda Feccia, Gian Carla Gaggero, Rosa Popolizio, Roberta Severino - Nizza Monferrato (AT); Marco Strazzabosco, Elisabetta Brun, Maria Simoncini, Chiara Alberta Mesturino, Francesco Zen - Noventa Vicentina (VI); Giovanni Paolo Carlesi, Simona Garrone - Novi Ligure (AL); Alfonso Gigante, Anna Maria Cicalò, Rossella Cau, Concetta Clausi - Nuoro; Agostino Paccagnella, Maria Sambataro, Edward Kiwanuka, Tiziana Citro, Barbara Almoto, Eros Bagolin, Daniela Pizzolato, Alessandra Mauri Oderzo (TV); Alberto Manconi, Giancarlo Tonolo, Giovanni Domenico, Filigheddu, Angela Assunta Pinna, Antonello Carboni, Maria Filippina Angius, Lucia Canu, Sara Cherchi - Olbia (OT); Silvia Calebich, Cinzia Burlotti, Alfonso Piccoli - Ome (BS); Giuseppe Saglietti - Omegna (VB); Sergio Cabras, Barbara Figus, Ignazia Oppo
- Oristano; Francesco Mastinu, Maria Franca Mulas, Gianfranco Madau, Marina Cossu, Simonetta Zoccheddu, Marilena Atzeni, Gabriele Idda, Monica Obinu - Oristano; Giovanni Cicioni, Chiara Di Loreto, Massimo Bracaccia - Orvieto (TR); Mario Balsanelli, Mauro Fetonti, Paola Sambo - Ostia (RM); Tommasina Sorrentino, Andrea Del Buono, Iole Gaeta, Angelo Annunziata, Pietro Cannavale, Nunziata Di Palma, Carolina Federico - Ottaviano (NA); Elio Secchi, Maria Antonietta Angotzi, Salvatore Loddoni, Irene Brundu, Franca Careddu, Antonietta Becciu, Gabriella Piras - Ozieri (SS); Giuseppe Torchio, Adolfo Carlo Alberto Bianchi, Gian Battista Colucci, Patrizia Palumbo, Barbara Saviori - Paderno Dugnano (MI); Angelo Avogaro, Daniela Bruttomesso, Cristina Crepaldi, Giampaolo Fadini, Gabriella Guarnieri, Saula de Kreutzenberg, Alberto Maran, Monica Vedovato Padova; Annunziata Lapolla, Rosanna Toniato, Giuseppe Bax, Barbara Bonsembiante, Claudio Cardone, Maria Grazia Dalfrà, Alessandra Gallo, Michela Masin, Francesco Piarulli, Antonino Pipitone, Giovanni Sartore - Padova; Francesco D'Agati, Lorenza Patrizia Cipolla, Antonella Biondo - Palermo; Maria Antonella Fulantelli - Palermo; Daniela Gioia, Michela Conti - Palermo; Giuseppe Mattina, Lorenza Patrizia Cipolla - Palermo; Giuseppe Mattina, Maria Vaccaro, Iana Costa - Palermo; Giovanni Ridola - Palermo; Giovanni Grossi, Fiorella De Berardinis, Rosanna Piro, Anna Semaforico, Assunta Montalto Paola (CS); Maria Cristina Cimicchi, Diletta Ugolotti, Daina Filippi, Marina Ferrari - Parma; Sergio Michele Tardio, Maria Cristina Calderini, Maria Grazia Magotti, Laura Franzini, Raffaele Napolitano - Parma; Ivana Zavaroni, Alessandra Dei Cas, Elisa Usberti, Valentina Ridolfi, Monica Antonini, Michela Marina, Elisabetta Marchesi, Nadia Anelli - Parma; Paola Del Sindaco, Enio Picchio, Gianluigi Guercini, Laura Piastrella, Massimo Arcelli - Perugia; Adriano Spalluto, Luigi Maggiulli, Massimo Badiali - Pesaro; Giuliana La Penna, Agostino Consoli - Pescara; Roberto Anichini, Lucia Loredana Merluzzo, Elena Ceccanti, Alessia Lazzarini, Milva Lazzeretti, Irene Howard, Secondina Viti, Alice Magiar - Pescia (PT); Anna Rosa Bogazzi, Giovanna Bendinelli, Massimo Rivelli, Cristina Vietti - Pianezza (TO); Lucia Briatore, Giacomo Calvo, Brunella Falco - Pietra Ligure (SV); Carlo Antona, Daniele De Vido - Pieve di Cadore (BL); Alessandro Ozzello, Enrico Pergolizzi, Daniela Gaia, Paola Gennari, Giuliana Micali Pinerolo (TO); Valerio Gherardini, Leonardo Moretti, Francesca Iovine, Chiara Goretti, Monica Bientinesi, Luciana Landi - Piombino (LI); Roberto Miccoli, Cristina Bianchi, Giuseppe Penno, Francesca Venditti, Stefano Del Prato - Pisa; Roberto Anichini, Alessandra De Bellis, Anna Tedeschi, Lisetta Butelli, Rossella Picciafuochi, Manola Gioffredi, Roberto Gori, Tiziana Bruschi, Raffaella Malagoli - Pistoia; Roberto Giubbolini, Sfefania Machetti, Susanna Sansi Roasamaria Grisanti - Poggibonsi (SI); Emilia Martedì, Francesco Nappo - Portici (NA); Gaetana Cossu, Pietro Deliperi - Porto Torres (SS); Cristiano Fongher, Anna Gnan - Porto Viro (RO); Giovanna Villani, Claudia Cancro, Stefano Anelli - Portoferraio (LI); Massimo Moretti, Milena Zanon, Anna Battiston, Anna Del Bianco, Michela Signorato Portogruaro (RO); Vincenzo Mazzini, Marina Orlandi, Maria Cristina Pollace - Portomaggiore (FE); Armando Zampino, Rosa Sinisi, Maria Natale, Giuseppe Citro - Potenza; Maria Calabrese, Lucia Ianni, Monica Lorenzetti, Angela Marsocci, Sandra Guizzotti, Ida Innocenti, Annalia Noci, Ahoua Sagnon, Romina Fioravanti, Paola Mestrini Prato; Giosuè Ghilardi, Patrizia Fiorina - Priario (BG); Salvatore Turco, Antongiulio Faggiano, Giovanna Donnarumma, Nicola Tafuri, Mariella Andretti, Barbara Tramontano - Quarto (NA); Francesco Cabasino, Fernando Farci, Alberto Atzori, Mariangela Ghiani, Irene Siotto, Marianna Sedda, Alì Manis, Carmela Loddo, Ilaria Loddo, Lucia Pisano, Paola Seguro, Annamaria Cuomo, Lucilla Orlando, Giovanni Battista Olanda - Quartu S’Elena (CA); Michelina Massenzo 
Quattromiglia di Rende (CS); Achiropita Pucci, Barbara Greco Quattromiglia di Rende (CS); Paolo Di Bartolo, Cipriana Sardu Ravenna; Giovanni Careddu, Raffaella Costa, Vilma Campora, Laura Anselmi, Andrea Corsi - Recco (GE); Celestino Giovannini - Reggio Calabria ; Domenico Mannino, Emira Dal Moro, Maurizio Postorino, Eugenio Alessi - Reggio Calabria ; Giovanni Perrone, Francesca Corazziere, Irene La Puzza - Reggio Calabria ; Pier Francesco Tripodi, Angela Mirto, Sergio Grasso, Giulia Zerbi-Cama, Antonella Giampaolo - Reggio Calabria; Valeria Manicardi, Prisco Sborbone, Eliana Gardini, Elisa Manicardi, Clelia Di Seclì, Patrizia Marrino, Rosa Trianni, Marina Greci - Reggio Emilia; Emilio Rastelli, Claudia Rastelli - Riccione (RN); Basilio Battisti, Anna Rita Aleandri, Maria Virginia Guidi, Rosaria Faraglia, Verena Lilli - Rieti; Rocco Bulzomì - Roma; Francesco Chiaramonte, Renato Giordano, Maria Giuseppina Migneco, Mauro Rossini, Natalia Visalli, Daniela Danna, Silvana Baldassarra, Romina Ralli, Samanta Roma, Orietta Pannozzo, Alessandra Cignetti, Bruna Facchiani, Claudia Righini - Roma; Mariano Pio D'Accinni, Donatella Paolucci, Anna D'Ubaldi, Maria Teresa D'Angelo, Manuela Fratini, Giovanni Masaro, Marco Pietrantoni, Roberta La Rosa - Roma; Maria Giuliano, Maria Grazia Pennafina, Pasquale Di Perna - Roma; Sergio Leotta, Concetta Suraci, Natalia Visalli, Roberto Gagliardi, Lucia Fontana, Maria Altomare, Silvia Carletti, Santina Abbruzzese, Letizia Bruschi, Roberta Lancione - Roma; Sebastiano Filetti, Susanna Morano, Marcella Santilli, Elisabetta Mandosi, Mara Fallarino, Marco Rossetti - Roma; Fabio Piergiovanni, Fiorella Massimiani, Angela Simonetta, Danila Fava, Fulvia De Luca, Giuliana Leacche, Teresa Giampietro, Rossella Guarino - Roma; Maurizio Poggi, Anna Penza, Francesca Piccirilli, Roberta Pisano, Annamaria Prioletta, Caterina Saponara - Roma; Raffaele Scalpone, Fabrizia Toscanella, Alessandro Scoppola, Lorena Mancini - Roma; Claudio Tubili, Lelio Morviducci, Maria Rosaria Nardone, Paola Fratoni - Roma; Daniela Cappelloni, Lina Lardieri, Alessandro Urbani, Tiziana Santucci, Gabriella del Monte, Irene Pellegrino, Franca Rauseo, Patrizia Alini - Roma; Giuseppe Armentano, Maria Grazia Restuccia, Giuseppe Vatrano Rossano (CS); Renzo Girardello, Renzo Gennaro, Lorena De Moliner, Annalisa Mattuzzi, Katja Speese,Elena Bettini, Fabiola Frisinghelli, Monica Falqui - Rovereto (TN); Giacomo Vespasiani, Illidio Meloncelli, Lina Clementi, Marianna Galetta, Valentina Marconi - S. Benedetto del Tronto (AP); Paolo Bordin, Maurizio Sacandi, Laura Perale, Luciana Dotto, Roberto Da Ros, Nella Pupin, Elena Rosso, Fabiola Zamparo - S. Daniele del Friuli (UD); Silvestre Cervone, Matteo Pontonio, Lucia De Angelis - S. Marco in Lamis (FG); Manola Nicoletti, Nazzareno Trojan, Tiziano Croatto, Rita Centis - S. Vito al Tagliamento (PN); Patrizia Li Volsi, Elisa Levis, Giorgio Zanette Sacile (PN); Carmela Vinci, Milena Zanon, Loredana Geretto, Cristina Toffolo, Maria Grazia Furlan - San Donà di Piave (VE); Vincenzo Sica, Raffaella Derai, Marina Armeni, Anna Bruna Urraci, Letizia Carreras, Elisabetta Cossu, Simonetta Mamusa, Maria Antonietta Pisano - San Gavino Monreale (VS); Salvatore De Cosmo, Anna Rauseo - San Giovanni Rotondo (FG); Marco Strazzabosco, Elisabetta Brun, Maria Simoncini, Chiara Alberta Mesturino, Francesco Zen - Sandrigo (VI); Roberto Sturaro, Maurizio Raffa, Federico Quattrocchi - Sanremo (IM); Anna Carbone, Cristina Gnocchi, Maria Rosa Anelli, Ester Fontana, Giuliana Alfoli - Sant' Angelo Lodigiano (LO); Maura Rosco, Giovanni Labarile - Santeramo (BA); Fabrizia Caucci - Sassari; Luca Lione, Dino Dessì - Savona; Mario Monachesi, Giovanni Carta, Mara Boschetti, Enrica Ceresola, Emanuela Venier - Savona; Stefano De Riu, Umberto Amelia - Scafati (SA); Francesco Calcaterra, Fedele Cataldi, Marina Miola - Schio (VI); Silvana Manfrini, Silvia Rilli, Gessica Tinti - Senigallia (AN); Alessio Lai, Barbara Locci, Donatella Putzu - Senorbi (CA); Stefano Genovese, Loredana Bucciarelli, Maurizio Rondinelli,
Monica Bulgheroni - Sesto S. Giovanni (MI); Stefano Gonnelli, Alice Cadirni, Italo Tanganelli - Siena; Karl Egger, Kerstin hofmann, Margareth Tanner, Heidrun Hohenegger - Silandro (BZ); Cristina Porru, Angela Canneddu, Mercedes Porcu - Siniscola (NU); Vittoria Sesta, Franca Daidone - Siracusa; Luigi Vincis, Viviana Orlandi, Cinzia Pilloni, Rossana Farci, Ilaria Pelligra, Giuseppina Renier - Sirai Carbonia (CI); Marco Mameli, Elvira Devigus, Anna Pala - Sorgono (NU); Giuseppe Felace, Ida Fumagalli, Paola Tosoni, Daniela Ovan, Silvia Giacomello, Nada Peressini, Fiorella Rossi - Spilimbergo (PN); Carlo Lalli, Mafalda Agliani, Maria Luisa Picchio, Maura Scarponi, Ludovico De Pascalis, Erika Bonucci - Spoleto (PG); Francesco Malci, Anita De Ciocchis, Chiara Moscatelli - Subiaco (RM); Barbara Macerola, Angelina Mandarino, Sandra Incani - Sulmona (AQ); Silvano Davì, Maria Ausilia Caccavale, Simona Borla, Marina Pognant Gros - Susa (TO); Ennio Lattanzi, Concettina Piersanti, Anna Piersanti, Irene Spinelli, Gabriella Quaranta, Silvia D'Ascanio - Teramo; Lorenzo De Candia - Terlizzi (BA); Antimo Aiello, Pietro Di Caro, Fabrizia Flocco, Agnese Franco, Maria Antonietta Lezzi, Anna Meo, Antonella Meo, Alfredo Puntillo, Giovanna Scarpina, Marco Tagliaferri, Celeste Vitale - Termoli (CB); Giovanni Cicioni, Maria Grazia Massarelli, Stefania Venturi - Terni; Augusto Travaglini, Patrizia Draghi - Terni; Elisa Forte, Lucilla Tamburro, Catia Palmacci, Maria Palma Abbate Terracina (LT); Stefania Deiana, Francesca Scanu - Thiesi (SS); Paolo Pomante - Tocco da Casauria (PE); Alberto Bruno, Paolo Cavallo Perin, Ezio Ghigo, Massimo Porta, Paola Scuntero, Rosanna Arcari, Silvana Bertaina, Simona Bo, Fabio Broglio, Graziella Bruno, Mariella Degiovanni, Paolo Fornengo, Giorgio Grassi, Valeria Inglese, Mauro Maccario, Giorgio Maghenzani, Saverio Marena, Valentino Martina, Pietro Passera, Gianluca Ruiu, Milena Tagliabue, Maria Zanone Torino; Aurora Grassi, Alberto Mormile, Anna Maria Ingaramo, Pietro Demurtas - Torino; Luca Monge, Gian Mario Boffano, Katia Macrì, Paola Maio - Torino; Luca Richiardi, Alessandra Clerico Torino; Cesare Dossena, Simona Bosoni - Tortona (AL); Francesca Novara, Daniela Mancuso, Francesca Cipro - Trapani; Paolo Acler, Tiziana Romanelli, Sandro Inchiostro, Massimo Orrasch, Cristina Faes, Silvia Clementi, Franca Endrizzi, Ilaria Nicolao - Trento; Carlo Antonio Bossi, Giancarla Meregalli, Annalisa Balini, Denise Berzi, Anna Pulcina - Treviglio (BG); Agostino Paccagnella, Maria Sambataro, Edward Kiwanuka, Tiziana Citro, Barbara Almoto, Eros Bagolin, Daniela Pizzolato, Alessandra Mauri - Treviso; Riccardo Candido, Elena Manca, Alessandra Petrucco, Elisabetta Caroli, Elisabetta Tommasi, Giuseppe Jagodnik, Nevia Daris, Rossella Alberti, Katja Tercelj, Elisabetta Presti, Sarah Perini, Elisa Del Forno - Trieste; Maria Antonietta Pellegrini, Laura Tonutti, Giorgio Venturini,Sandra Agus, Franco Grimaldi - Udine; Mauro Andreani, Federica Turchi, Maurizio Sudano, Gigliola Martinelli, Stefania Lani - Urbino (PU); Francesca Innelli, Piera Grammaldo, Angelo Vistocco - Vallo della Lucania (SA); Silvio Sposito, Renzo Rongioletti, Maria Candidi Velletri (RM); Anna Rosa Bogazzi, Giovanna Bendinelli, Massimo Rivelli, Cristina Vietti - Venaria Reale (TO); Ermanno Moro, Antonella Senesi - Venezia; Giuseppe Saglietti, Giuseppe Placentino, Antonella Schellino - Verbania Pallanza (VB); Roberto Mingardi, Luciano Lora, Cristina Stocchiero, Rachele Reitano, Mee Jung Mattarello, Giovanni Ronzani, Silvia Pegoraro, Matteo Rolandi, Veronica Baggio, Elisa Rancan - Vicenza; Marco Strazzabosco, Elisabetta Brun, Maria Simoncini, Chiara Alberta Mesturino, Francesco Zen - Vicenza; Mauro Giovanni Schiesaro, Giovanni Vita, Beatrice Cenci, Vania ampostrini, Ilaria Basso, Augusta Turrini - Villafranca Veronese (VR); Paola Pisanu - Villasimius (CA); Ida Mangone, Enrico Cazzaniga, Giovanni Sifarelli - Vimercate (MB); Claudio Grande, Claudia Arnaldi, Paolo Fiorentini, Enrico Capotorti, Angela Del Prete - Viterbo; Umberto 
Citation: Tondini S, Boemi M, Marnini P, Bollati PM, Fiore V, et al. (2015) Quality of Healthcare Provided to Elderly with Type 2 Diabetes: Data from the AMD* Annals Initiative. J Diabetes Metab 6: 542. doi:10.4172/2155-6156.1000542

Iannaccone, Mauro Ragonese, Caterina Scoponi, Laura Tilaro, Silvia Pelliccioni, Rossana Slongo, Emanuela Vita - Viterbo; Arcangela Garofalo, Filippo Vitale, Giuseppina Saggio, Biagia Campanella Vittoria (RG); Andrea Del Buono, Tommasina Sorrentino, Teresa Borrelli, Mariarosaria Matrecano - Volla (NA); Aldo Giuseppe Morea, Lucia Bondesan, Sandro Perbellini - Zevio (VR).

\section{References}

1. Zhang $P$, Zhang $X$, Brown J, Vistisen D, Sicree R, et al. (2010) Global healthcare expenditure on diabetes for 2010 and 2030. Diabetes Res Clin Pract 87: 293-301.

2. Sinclair A, Morley JE, Rodriguez-Mañas L, Paolisso G, Bayer T, et al. (2012) Diabetes mellitus in older people: position statement on behalf of the International Association of Gerontology and Geriatrics (IAGG)), the European Diabetes Working Party for Older People (EDWPOP), and the International Task Force of Experts in Diabetes. J Am Med Dir Assoc 13: 497-502.

3. The Diabetes Control and Complications Trial Research Group (1993) The Effect of Intensive Treatment of Diabetes on the Development and Progression of Long-Term Complications in Insulin-Dependent Diabetes Mellitus. N Engl J Med 329: 977-986.

4. [No authors listed] (1998) Intensive blood-glucose control with sulphonylureas or insulin compared with conventional treatment and risk of complications in patients with type 2 diabetes (UKPDS 33). UK Prospective Diabetes Study (UKPDS) Group. Lancet 352: 837-853.

5. Ohkubo Y, Kishikawa H, Araki E, Miyata T, Isami S, et al. (1995) Intensive insulin therapy prevents the progression of diabetic microvascular complications in Japanese patients with non-insulin-dependent diabetes mellitus: a randomized prospective 6-year study. Diabetes Res Clin Pract 28: 103-117.

6. Gaede P, Vedel P, Larsen N, Jensen GV, Parving HH, et al. (2003) Multifactorial intervention and cardiovascular disease in patients with type 2 diabetes. $\mathrm{N}$ Engl J Med 348: 383-393.

7. Pyŏrälä K, Pedersen TR, Kjekshus J, Faergeman O, Olsson AG, et al. (1997) Cholesterol lowering with simvastatin improves prognosis of diabetic patients with coronary heart disease: a subgroup analysis of the Scandinavian Simvastatin Survival Study (4S). Diabetes Care 20: 614-620.

8. American Diabetes Association (2013) Standards of Medical Care in Diabetes. Diabetes Care 36: 11-66.

9. Guthrie B, Emslie-Smith A, Morris AD (2009) Which people with Type 2 diabetes achieve good control of intermediate outcomes? Population database study in a UK region. Diabe Med 26: 1269-1276.

10. Nicolucci A, Rossi MC, Arcangeli A, Cimino A, de Bigontina G, et al. (2010) Four-year impact of a continuous quality improvement effort implemented by a network of diabetes outpatient clinics: the AMD-Annals initiative. Diabet Med 27: $1041-1048$

11. Araki A, Ito $H$ (2009) Diabetes mellitus and geriatric syndromes. Geriatr Gerontol Int 9: 105-114.

12. Levey AS, de Jong PE, Coresh J, El Nahas M, Astor BC, et al. (2011) The definition, classification, and prognosis of chronic kidney disease: a KDIGO Controversies Conference report. Kidney Int 80: 17-28.

13. Maclsaac RJ, Tsalamandris C, Panagiotopoulos S, Smith TJ,McNeil KJ, et al (2004) Non-albuminuric renal insufficiency in type2 diabetes. Diabetes Care 27: $195-200$

14. Kramer HJ, Nguyen QD, Curhan G, Hsu CY (2003) Renal insufficiency in the absence of albuminuria and retinopathy among adults with type 2 diabetes mellitus. JAMA 289: 3273-3277.

15. Penno G, Solini A, Bonora E, Fondelli C, Orsi E, et al. (2011) Clinical significance of nonalbuminuric renal impairment in type 2 diabetes. J Hypertens 29: 1802-1809.
16. Patel A, ADVANCE Collaborative Group, MacMahon S, Chalmers J, Neal $B$ et al. (2007) Effects of a fixed combination of perindopril and indapamide on macrovascular and microvascular outcomes in patients with typer 2 diabetes mellitus (the ADVANCE trial): a randomized controlled trial. The Lancet 370 829-840.

17. Drury PL, Ting R, Zannino D, Ehnholm C, Flack J, et al. (2011) Estimated glomerular filtration rate and albuminuria are independent predictors of cardiovascular events and death in type 2 diabetes mellitus: the Fenofibrate Intervention and Event Lowering in Diabetes (FIELD) study. Diabetologia 54: 32-43.

18. Cholesterol Treatment Trialistsâ€ ${ }^{\mathrm{TM}}$ (CTT) Collaboration, Baigent $\mathrm{C}$, Blackwell L, Emberson J, Holland LE, et al. (2010) Efficacy and safety of more intensive lowering of LDL cholesterol: a meta-analysis of data from 170,000 participants in 26 randomised trials. Lancet 376: 1670-1681.

19. [No authors listed] (1994) Randomised trial of cholesterol lowering in 4444 patients with coronary heart disease: the Scandinavian Simvastatin Survival Study (4S) Lancet 344: 1383-1389.

20. Jellinger PS, Dickey RA, Ganda OP, Mehta AE, Nguyen TT, et al. (2000) AACE medical guidelines for clinical practice for the diagnosis and treatment of dyslipidemia and prevention of atherogenesis. Endocr Pract 6: 162-213.

21. Associazione Medici Diabetologi, Società Italiana di Diabetologia (2010) Standard italiani per la cura del diabete mellito. Edizione Infomedica.

22. Sue Kirkman M, Briscoe VJ, Clark N, Florez H, Haas LB, et al. (2012) Diabetes in older adults: a consensus report. J Am Geriatr Soc 60: 2342-2356.

23. Szadkowska I, Stanczyk A, Aronow WS, Kowalski J, Pawlicki L, et al. (2010) Statin therapy in the elderly: a review. Arch Gerontol Geriatr 50: 114-118.

24. Canadian Diabetes Association Clinical Practice Guidelines Expert Committee Meneilly GS, Knip A, Tessier D (2013) Diabetes in the elderly. Can J Diabetes 37 Suppl 1: S184-190.

25. American Geriatrics Society Expert Panel on Care of Older Adults with Diabetes Mellitus, Moreno G, Mangione CM, Kimbro L, Vaisberg E (2013) Guidelines abstracted from the American Geriatrics Society Guidelines for Improving the Care of Older Adults with Diabetes Mellitus: 2013 update. J Am Geriatr Soc 61: 2020-2026.

26. Anderson RJ, Bahn GD, Moritz TE, Kaufman D, Abraira C, et al. (2011) Blood pressure and cardiovascular disease risk in the Veterans Affairs Diabetes Trial. Diabetes Care 34: 34-38

27. ACCORD Study Group, Cushman WC, Evans GW, Byington RP, Goff DC Jr, et al. (2010) Effects of intensive blood-pressure control in type 2 diabetes mellitus. N Engl J Med 362: 1575-1585.

28. American Diabetes Association (2013) Standards of medical care in diabetes--2013. Diabetes Care 36 Suppl 1: S11-66.

29. Alavi A, Sibbald RG, Mayer D, Goodman L4, Botros M5, et al. (2014) Diabetic foot ulcers: Part I. Pathophysiology and prevention. J Am Acad Dermatol 70: 1.

30. Matthews DR, Stratton IM, Aldington SJ, Holman RR, Kohner EM, et al (2004) Risks of progression of retinopathy and vision loss related to tight blood pressure control in type 2 diabetes mellitus: UKPDS 69. Archives of Ophthalmology 122:1631-1640.

31. Agardh E, Agardh CD, Hansson-Lundblad C (1993) The five-year incidence of blindness after introducing a screening programme for early detection of treatable diabetic retinopathy. Diabet Med 10: 555-559.

32. Mohamed Q, Gillies MC, Wong TY (2007) Management of diabetic retinopathy: a systematic review. JAMA 298: 902-916.

33. Grabowski DC, Ellis JE (2001) High body mass index does not predict mortality in older people: analysis of the Longitudinal Study of Aging. J Am Geriatr Soc 49: 968-979. 